\title{
Triboelectric behaviors of materials under high speeds and large currents
}

\author{
Yonghen ZHANG ${ }^{1, *}$, Zhenghai YANG ${ }^{1,2}$, Kexing Song ${ }^{1}$, Xianjuan PANG ${ }^{1}$, Bao SHANGGUAN ${ }^{1}$ \\ ${ }^{1}$ Key laboratory of material tribology, Henan University of Science and Technology, Luoyang 471023, China \\ ${ }^{2}$ Wuhan Research Institute of Materials Protection, China Academy of Machinery Science and Technology, Wuhan 430030, China \\ Received: 04 May 2013 / Revised: 13 August 2013 / Accepted: 22 August 2013 \\ (C) The author(s) 2013. This article is published with open access at Springerlink.com
}

\begin{abstract}
Using special testers, the triboelectric behaviors of several materials were investigated in this paper under the conditions of high speeds and large currents. The obtained results revealed that the tribological behaviors and current-conducting characteristics have complicated interrelationships. Worsening in the servicing conditions can obviously deteriorate the tribological as well as electrical behaviors; high sliding speeds and large electrical currents can worsen the tribological and electrical conductivity properties, while an appropriate contact pressure can benefit the electrical contact properties. Further analyses reveal that the worsening effects of the above factors, such as frictional heat, arc discharge, arc heat, and surface morphology, result in poor triboelectric contact performance. Among these, the electric arc is one of the most serious factors, because the occurrence of an electric arc may cause severe oxidation, melting, and roughening of the contact surface, thereby causing deterioration in the current-conducting quality as well as material loss.
\end{abstract}

Keywords: triboelectric system; current-carrying; working condition; arc

\section{Introduction}

Triboelectric pairs refer to the functional pairs in the electric conductivity process: These pairs have been widely used in railway pantographs/contact line systems, reflux brusher and axle systems, power generator and motor carbon brush/electrode systems, all types of switches, contactors, connectors, and so on [1-5]. As the working conditions gradually worsen, it becomes difficult to meet the severe servicing demands by means of existing technologies. (To achieve speeds of more than $100 \mathrm{~m} / \mathrm{s}$, the required current density is more than $3 \mathrm{~A} / \mathrm{mm}^{2}$ with higher reliability.) Triboelectric issues have become one of the most important problems that restrict the development of the abovementioned areas [6,7]. Investigating triboelectric pairs has become one of the most urgent issues for tribologists.

\footnotetext{
* Corresponding author: Yongzhen ZHANG.

E-mail: yzzhang@mail.haust.edu.cn
}

Triboelectric issues include not only the coupling behaviors of current conduction but tribology itself (Fig. 1). Such a functional system includes problems related to electrical contact, tribology, material science, mechanics, heat transfer, physics, chemistry, etc.; these problems attracted the attention of researchers in the early 1920s $[8,9]$. In fact, all the factors included in a complex triboelectric system influence the working behaviors in substantially complicated ways; for example, heat generation can be composed of arc thermal heat, electric resistance heat, frictional heat, environmental temperature, humidity, and atmospheric influences on the triboelectric behaviors with variable tendencies, as well as multi-failure mechanisms, such as mechanical wear, arc erosion, and oxidation, can simultaneously exist $[10,11]$. These relationships can be summarized into three groups, namely, frictional and conductive contacts, mechanical wear and electrical damage, and current-carrying qualities and tribological performance: Studies have been aimed to realize relatively better performances taking into consideration 


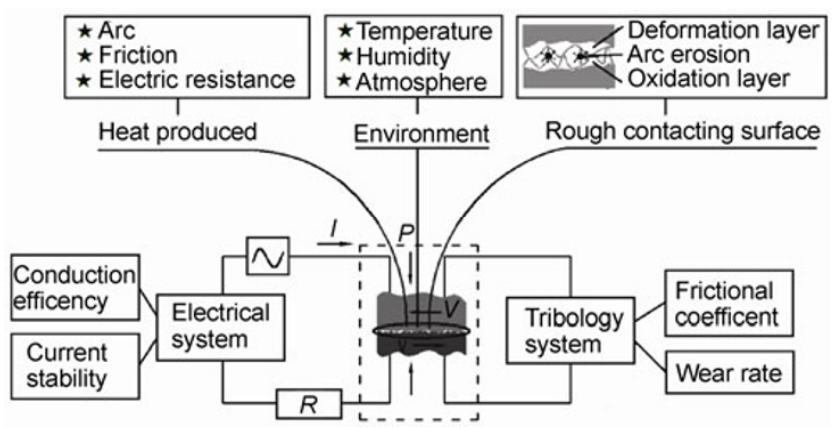

Fig. 1 Triboelectric system.

the above three parameters [10-16]. Therefore, current, load, relative sliding speed on current-carrying friction, and wear behavior of different typical currentcarrying friction materials have been studied and mechanisms for arc generation and their combined effects on contact behaviors have been discussed.

\section{Experimental details}

\subsection{Testing apparatus}

The testing apparatus was composed of pins and a disc, which is schematically shown in Fig. 2. During testing, two pin specimens were attached to the highspeed rotating disk: The current flows from one pin sample to the other pin specimen via the disc sample; the current finally flows into the power supply. The arc strength is measured using photosensitive diode arrays. Other testing parameters such as the dynamic current, voltage, and friction are simultaneously detected using special transducers. In this study, the parametric ranges were selected as follows: sliding speed, 0-100 m/s; load, 30-500 N; and current, 0-300 A. For ensuring reliable contact, all the samples are pre-grinded before testing.

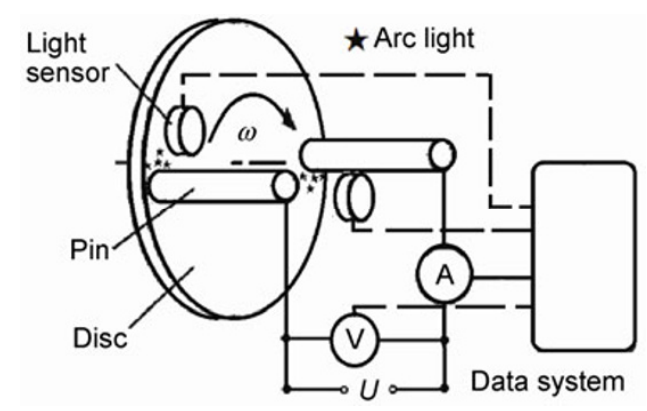

Fig. 2 Schematic illustration of high-speed triboelectric tester.

\subsection{Materials and data analyses}

The disk specimens were fabricated using commercial chromium bronze (QCr0.5), and the pin samples included (1) three commercial strip materials (copperbase powder metallurgy strip (PM), metal-impregnated carbon strip (MC), and carbon/carbon composite strip (C/C)); (2) two self-made materials (copper/graphite powder metallurgy and $0.6 \%$ alumina-reinforced copper matrix); and (3) pure copper.

The worn surfaces were observed using a scanning electron microscope (SEM) and a 3D topography profile meter. The triboelectric properties were evaluated using the friction coefficient, wear rate, current-carrying efficiency, current-carrying stability, arc rate [5], and arc energy [10].

The current-carrying efficiency can be calculated using

$$
\eta=\frac{A_{\mathrm{D}}}{A_{\mathrm{S}}} \times 100 \%
$$

where the current-carrying efficiency $\eta$ is expressed in $\%, A_{\mathrm{D}}$ denotes the dynamic current, and $A_{\mathrm{S}}$ denotes the static electric current.

The current-carrying stability can be calculated using the following equation:

$$
\begin{gathered}
S=\frac{\frac{1}{n} \sum_{i=1}^{n}\left(A_{i}-\bar{A}\right)^{2}}{\bar{A}} \times 100 \% \\
\bar{A}=\frac{1}{n} \sum_{i=1}^{n} \mathrm{~A}_{i}
\end{gathered}
$$

where $A_{i}$ denotes the instantaneous current value.

The parameters $\eta$ and $S$ are jointly used for the evaluation of current-conducting performance. Better current-carrying qualities can be obtained when the current-carrying efficiency is relatively larger and current-carrying stability is smaller.

\section{Results and discussion}

\subsection{Influences of working conditions on tribological properties and current-carrying qualities}

\subsubsection{Influences of testing conditions on tribological properties}

Figure 3 shows the friction coefficient and wear rate of the $\mathrm{C} / \mathrm{C}$ material for different sliding speeds and 

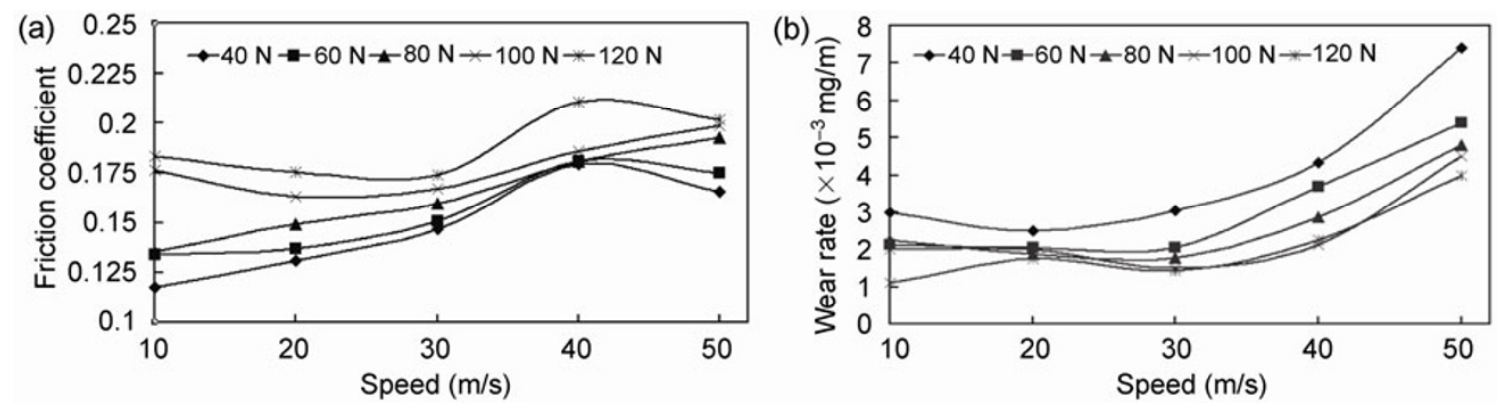

Fig. 3 Influences of sliding speed and contact pressure on tribological properties (constant current: 100 A): (a) friction coefficient, (b) wear rate.

contact pressures under a constant current of $100 \mathrm{~A}$. The results show that the friction coefficients initially increase with an increase in the sliding speed and then start decreasing when the sliding speed is over $40 \mathrm{~m} / \mathrm{s}$. Generally, with regard to the contact pressure, an increase in the load causes an increase in the friction coefficients, but a decrease in the wear rates.

The influences of the electric current on the friction coefficient and wear rate of the $\mathrm{C} / \mathrm{C}$ material under different sliding speeds are shown in Fig. 4. Evidently, the effects of current on the tribological properties are different under different sliding speeds. When the speed is less than $40 \mathrm{~m} / \mathrm{s}$, the friction coefficient decreases with an increase in the current, whereas the friction coefficient increases with an increase in the current when the speed is over $40 \mathrm{~m} / \mathrm{s}$. This suggests that the friction mechanisms in $\mathrm{C} / \mathrm{C}$ materials can change for different sliding speeds.

The influence of the electric current on the wear rates remained almost the same under all the sliding speeds under investigation. This implies that both sliding speed and current have a worsening influence on the wear properties. Further investigations reveal that the current influence is larger at relatively lower sliding speeds. Further, the sliding speed exacerbates if the current is above $130 \mathrm{~A}$.

The influences of the contact pressure on the tribological performances of $\mathrm{C} / \mathrm{C}$ materials for a sliding speed of $20 \mathrm{~m} / \mathrm{s}$ in the presence and absence of an electric current are shown in Fig. 5. Evidently, upon comparing both the conditions, it is evident that the friction coefficient is independent of the load; however, the friction coefficient dramatically decreases (down to 0.15) in the presence of an electric current. On the other hand, the presence of a current modifies the behavior of the contact pressure on the wear rate: As the contact pressure increases, the wear rate of the $\mathrm{C} / \mathrm{C}$ material increases in the absence of electricity, but it significantly decreases in the presence of a current; this suggests that an increase in the contact pressure might promote the lowering of wear losses.

Figure 6 shows the tribological properties of different materials with respect to the contact pressure, current, and relative sliding speed. It is clear that the influences of contact pressure on the tribological behaviors vary with the material (Figs. 6(a) and (b)). The wear rates
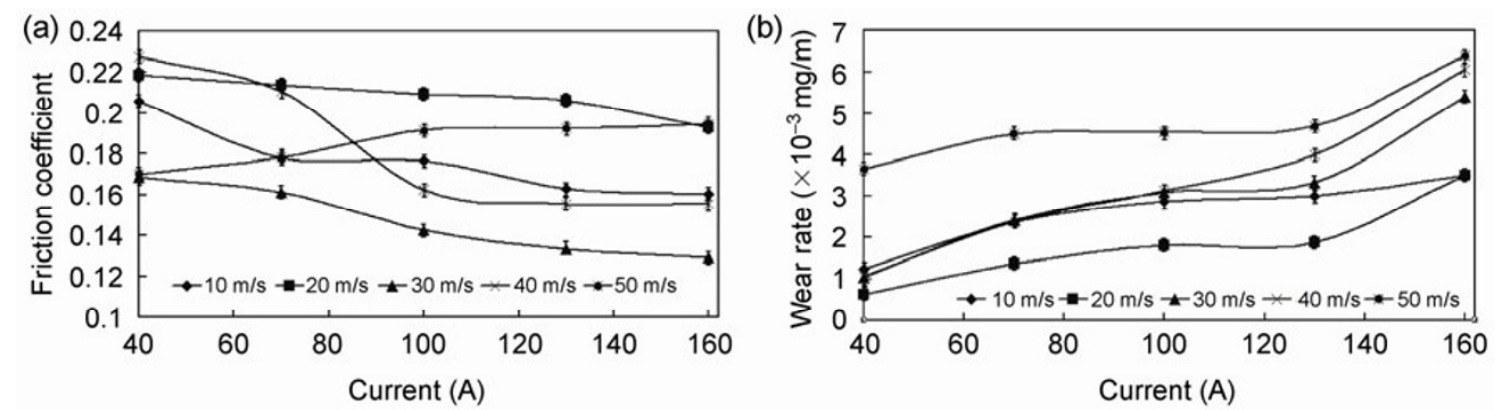

Fig. 4 Influences of current on tribological properties (constant load: $80 \mathrm{~N}$ ): (a) friction coefficient, (b) wear rate. 

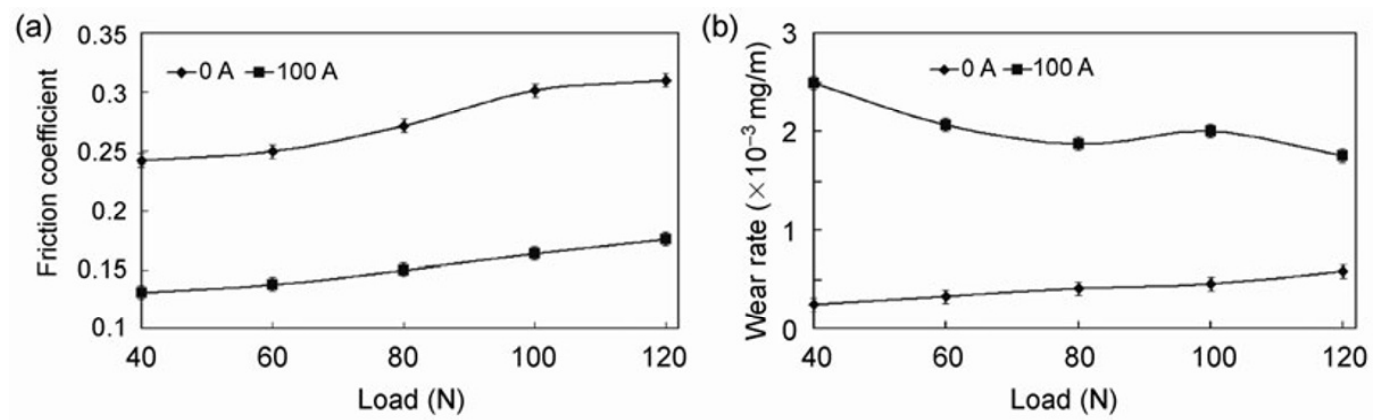

Fig. 5 Influences of contact pressure on tribological properties in the presence and absence of current: (a) friction coefficient, (b) wear rate.
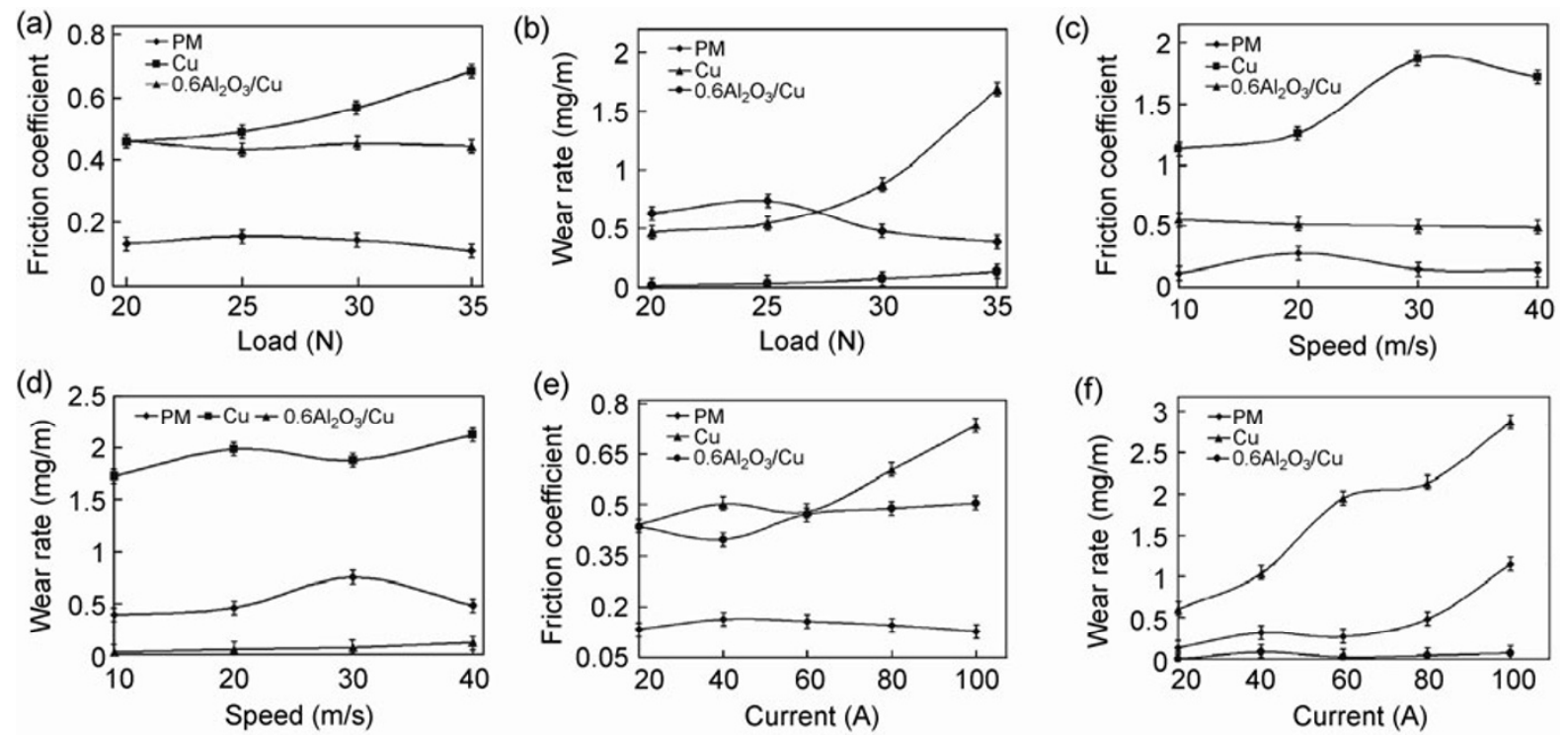

Fig. 6 Influences of contact pressure, sliding speed, and current on the friction coefficient and wear rates of different materials (constant current: $40 \mathrm{~A}$ ).

of pure copper and $0.6 \%$ alumina-reinforced copper matrix materials increase with the contact pressure, while the wear rate of the PM material roughly decreases with an increase in the contact pressure. With regard to the friction coefficient, increasing trends can be seen for all the three materials with an increase in the contact pressure.

The influences of sliding speed and current on the tribological properties of different materials are almost similar, i.e., increases in the sliding speed and current induce increases in the wear rate and friction coefficient. This suggests that high sliding speeds and large currents are detrimental to the tribological characteristics.

Above all, the intrinsic properties of materials and experimental conditions such as relative sliding speeds, loads, and currents obviously influence the frictional and wear-and-tear behaviors of triboelectric pairs. However, relatively high sliding speeds and large currents are obviously detrimental to the tribological properties.

\subsubsection{Influences of testing conditions on current-carrying qualities}

Figure 7 shows the plots of current-carrying qualities of C/C materials against current (constant load: $80 \mathrm{~N}$ ). Evidently, with an increase in the current, the currentcarrying efficiency and current-carrying stability decrease. This implies that the current-carrying qualities diminish under relatively larger currents. Besides, the experimental results reveal that the current-carrying qualities diminish dramatically if the current is larger than $80 \mathrm{~A}$ or the sliding speed is greater than $40 \mathrm{~m} / \mathrm{s}$. Therefore, higher sliding speeds 

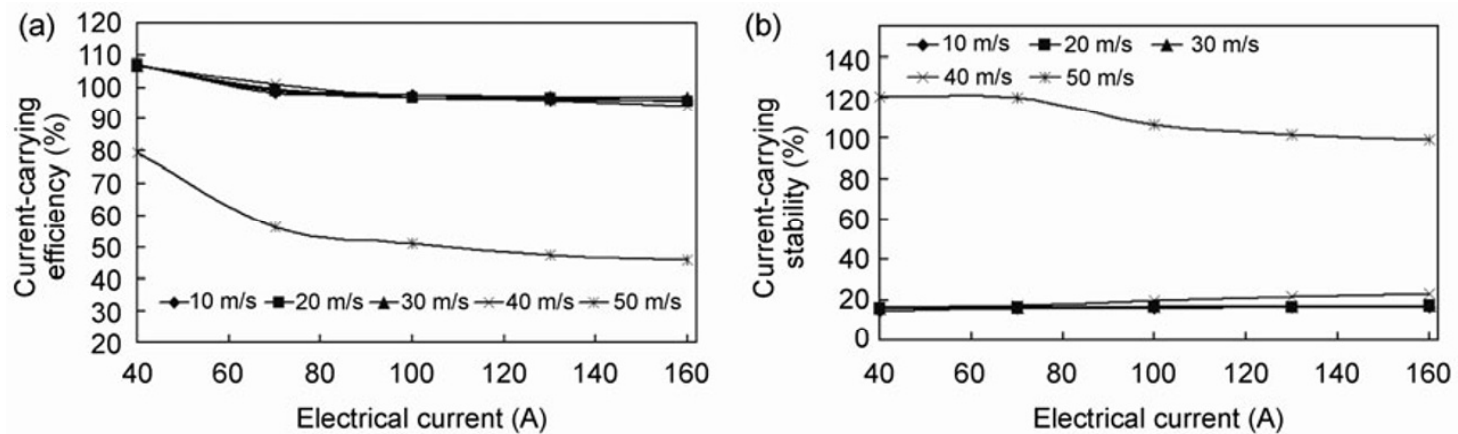

Fig. 7 Influences of current on current-carrying qualities: (a) current-carrying efficiency, (b) current-carrying stability.

and larger currents can not only worsen the tribological properties in a significant manner but also dramatically diminish the current-carrying qualities.

Figure 8 shows the plots of the current-carrying qualities of the $\mathrm{C} / \mathrm{C}$ material against differing loads (constant current: $100 \mathrm{~A}$ ). Evidently, for all the sliding speeds under investigation, as the contact pressure increases, the current-carrying efficiency as well as the current-carrying stability show obvious improvements, which implies that a relatively higher contact pressure helps in improving the current-carrying qualities.

Moreover, a critical pressure value exists until which the current-carrying qualities improve: If the contact pressure exceeds this critical threshold, the influence of the contact pressure on the currentcarrying qualities is markedly evident. Further, it can be noticed that the higher the sliding speed and larger the current, the higher is this critical pressure value. In other words, to obtain better current-carrying qualities, larger contact pressures are needed when subjected to higher speeds and larger currents.

Figure 9 shows the influences of sliding speeds on the current-carrying qualities (constant current density: $1.0 \mathrm{~A} / \mathrm{mm}^{2}$; constant pressure: $0.5 \mathrm{MPa}$ ). Evidently,
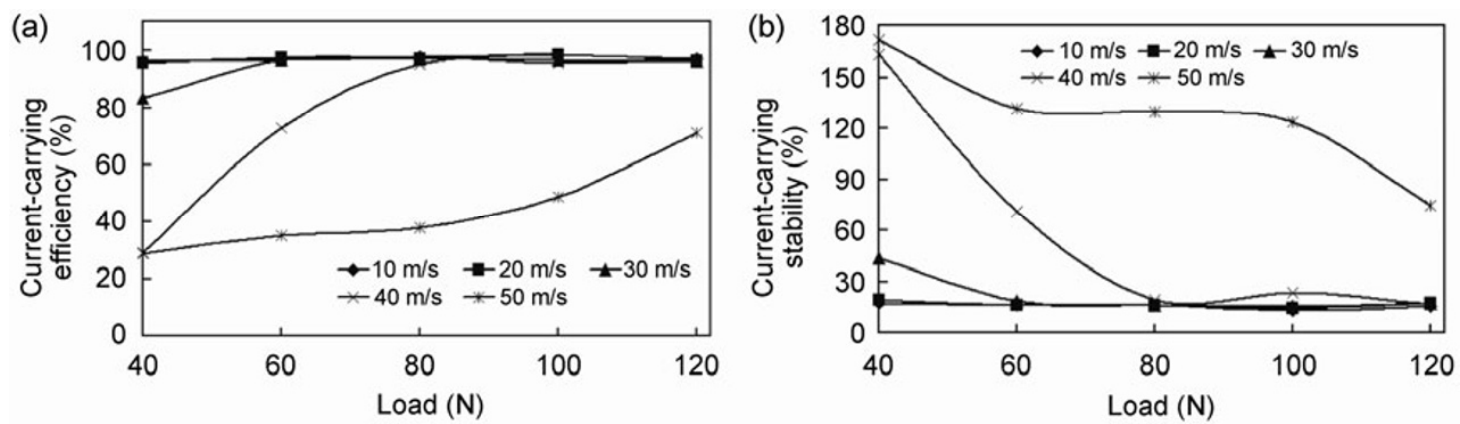

Fig. 8 Influences of different loads on the current-carrying qualities: (a) current-carrying efficiency, (b) current-carrying stability.
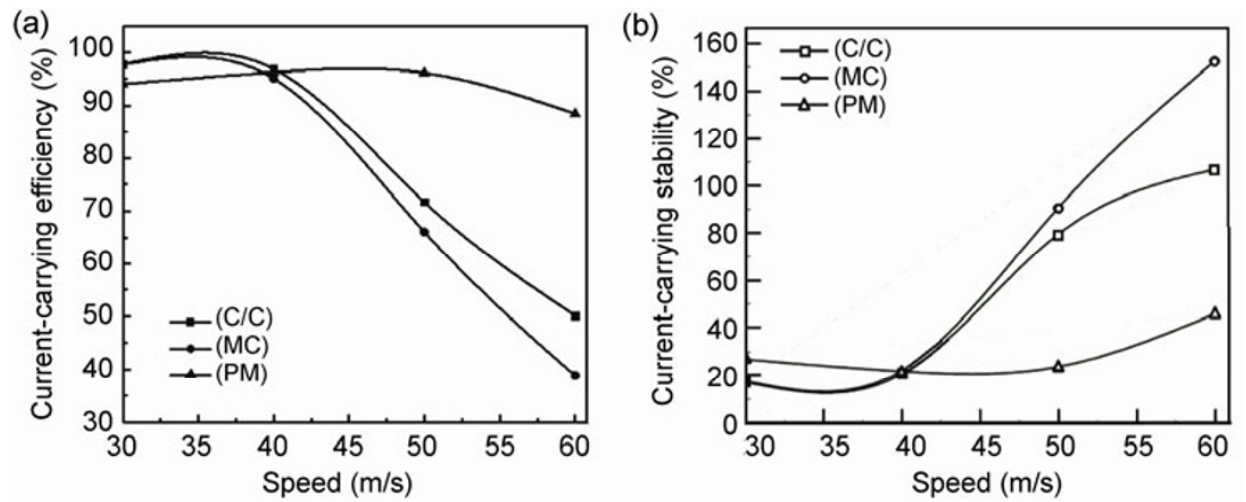

Fig. 9 Influences of speed on current-carrying qualities: (a) current-carrying efficiency, (b) current-carrying stability. 
although different materials possess different currentcarrying qualities, an increase in the sliding speed significantly diminishes the current-carrying qualities.

\subsection{Surface behaviors}

Figure 10 shows several types of wear mechanisms occurring on triboelectric surfaces. From this figure, it can be seen that almost all wear mechanisms occur on the worn surface, namely, (a) adhesion and oxidation, (b) plastic deformation and furrows, (c) plastic deformation layer, (d) arc erosion, (e) cracking due to surface melting, (f) layering as evinced by the MC material and the sharp distinction between the surface and core materials due to melting and seeping of copper (inset: heating pits), (g) gasification and evaporation of carbon from the $\mathrm{C} / \mathrm{C}$ material, (h) melting occurring in PM material, and (i) seriously melted surface of PM material. Therefore, the coexistence of multi-wear mechanisms is a distinctive property of triboelectric pairs.

In purely dry sliding pairs, besides electric arc erosion, no new wear mechanism is present. Generally, all the wear mechanisms occurring in purely dry sliding pairs become dramatically significant due to the interference of electric resistance heating and arc heating during the deterioration of surface materials.

Figure 11 shows the temperature curves of the pin specimens. The measurement point is located $2 \mathrm{~mm}$ from the contact surface. Evidently, with an increase in the sliding speed or current density, the temperature increases. This suggests that both frictional heating and electrical heating induce dramatic increases in the surface temperature. Moreover, a high surface temperature can result in severe material deterioration.

The oxidation of the friction surface is more significant at higher surface temperatures in triboelectric pairs in the presence of an electric current as compared to that in the absence of a current [6]. Table 1 and Fig. 12 enumerate the measurement of the surface constituents; it is distinctly clear that the oxygen content on the sliding surface with current is much higher than that without current, therefore the higher the carried current, the more severe is the oxidation.
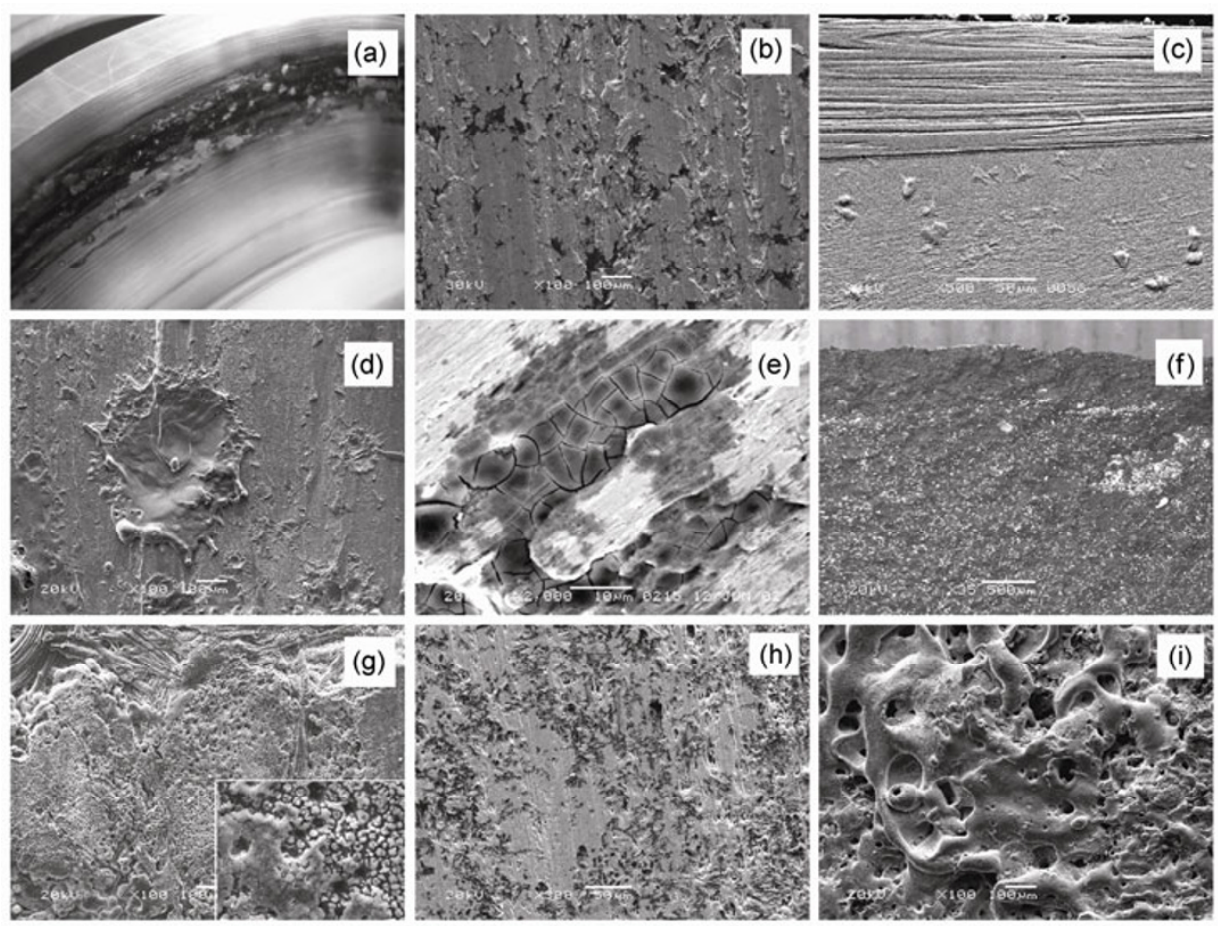

Fig. 10 Wear mechanisms induced by electrical friction: (a) adhesion and oxidation, (b) plastic deformation and furrows, (c) plastic deformation layer, (d) spillage surface after arc erosion, (e) cracked and worn surface after melting, (f) longitudinal section of MC (due to melting and seeping), (g) worn surface of C/C (due to gasification and evaporation), (h) melting on surface of PM, and (i) seriously melted surface of PM. 

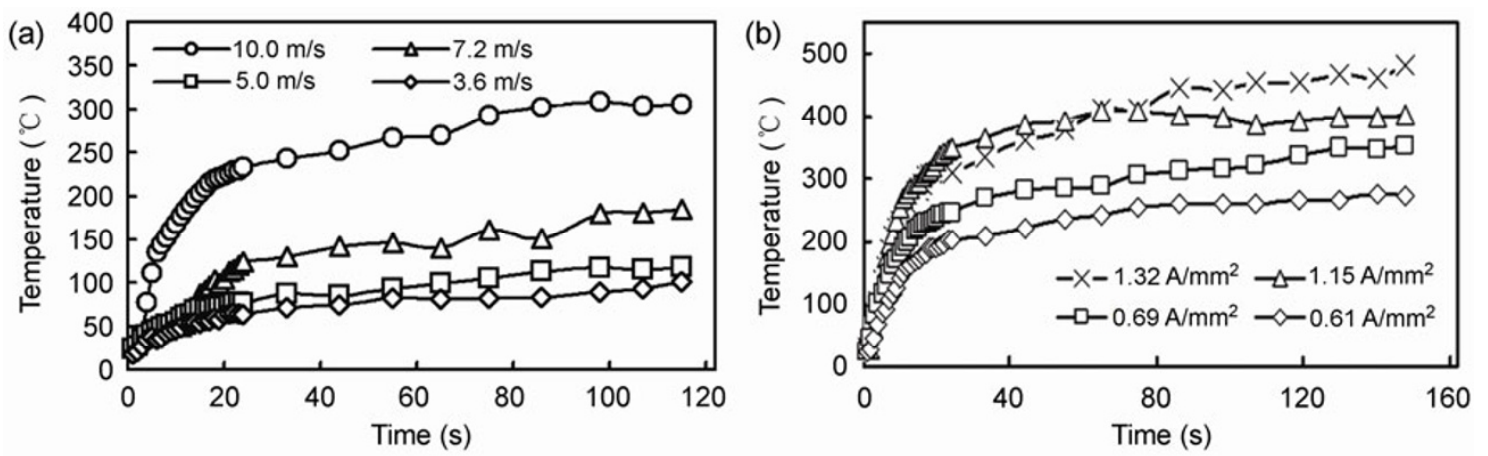

Fig. 11 Variations in the temperatures of specimens: (a) speed, (b) current.
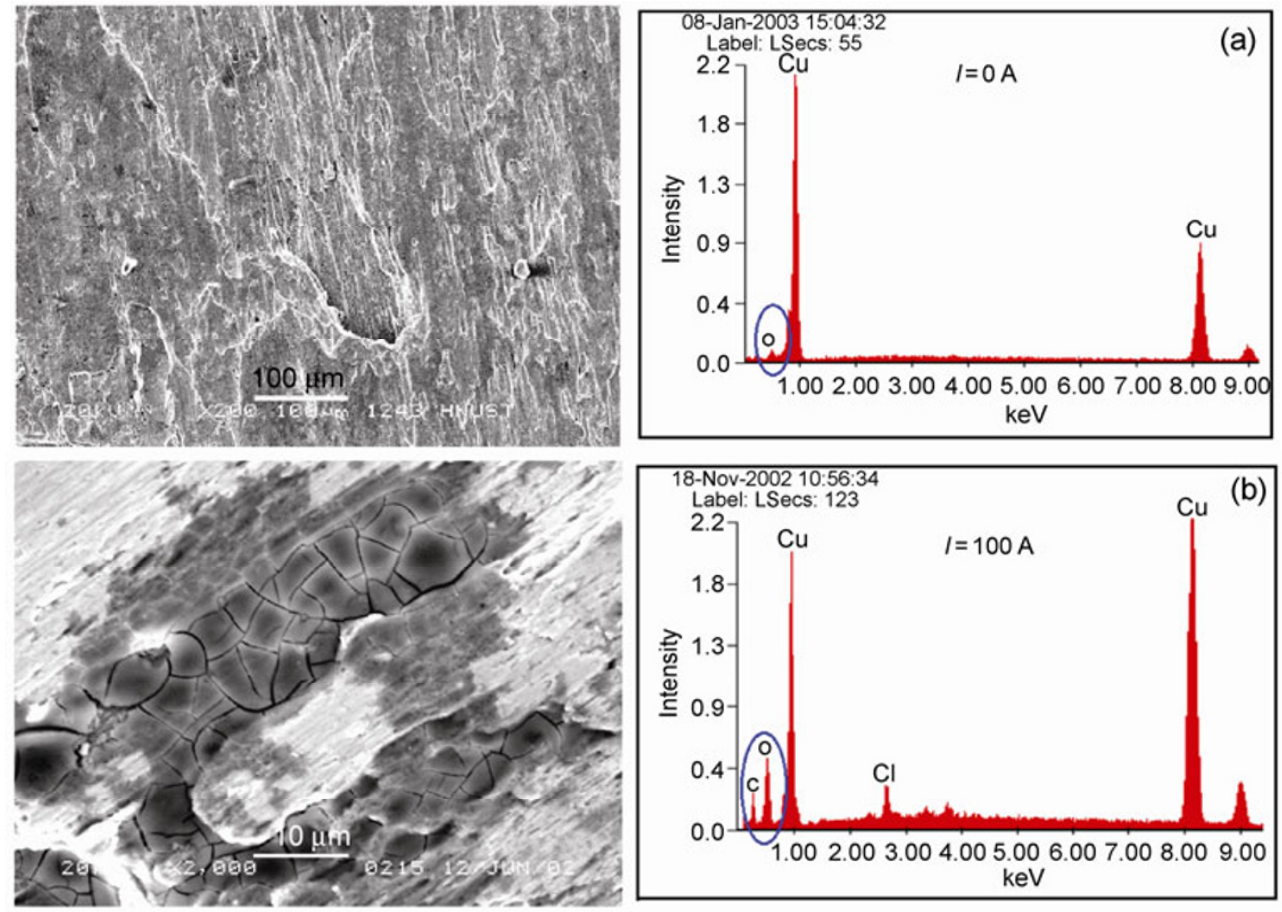

Fig. 12 Oxidation on worn surfaces: (a) without current, (b) with current.

Table 1 XPS analysis of different contents on different worn surfaces under different arc energies.

\begin{tabular}{cccc}
\hline & $\mathrm{PM}$ & $\mathrm{MC}$ & $\mathrm{C} / \mathrm{C}$ \\
\hline Low arc & $\mathrm{Cu}, \mathrm{Zn}, \mathrm{FeO}, \mathrm{Fe}$ & $\mathrm{C}, \mathrm{Pb}, \mathrm{Cu}, \mathrm{Sb}$ & $\mathrm{C}, \mathrm{Cu}, \mathrm{Pb}_{3} \mathrm{O}_{4}$ \\
energy $(10 \mathrm{~J})$ & & & \\
High arc & $\mathrm{Cu}, \mathrm{Zn}, \mathrm{Fe}, \mathrm{CuO}$, & $\mathrm{C}, \mathrm{Pb}, \mathrm{Cu}$, & $\mathrm{C}, \mathrm{Cu}, \mathrm{Pb}_{3} \mathrm{O}_{4}$, \\
energy $(100 \mathrm{~J})$ & $\mathrm{Cu}_{2} \mathrm{O}$ & $\mathrm{PbO}, \mathrm{Sb}_{2} \mathrm{O}_{4}$ & $\mathrm{Sb}_{2} \mathrm{O}_{4}$ \\
\hline
\end{tabular}

Figure 13 shows the microstructure of pure copper near the contact surface as compared to the original microstructure; evidently, the material deformation with current is more obvious than that without current. Severe deformation of material near the sliding surface leads to lower friction coefficient and serious wear losses.

Table 2 lists the surface roughness of the worn surface of the PM material under different test conditions. Evidently, with increases in the load (test Nos. 1 and 2) and increases in the current (test Nos. 3, 4 , and 5), the sliding surfaces become considerably rougher. Similarly, a poor surface quality is revealed when the sliding speed increases (test Nos. 6, 7, and 8). 

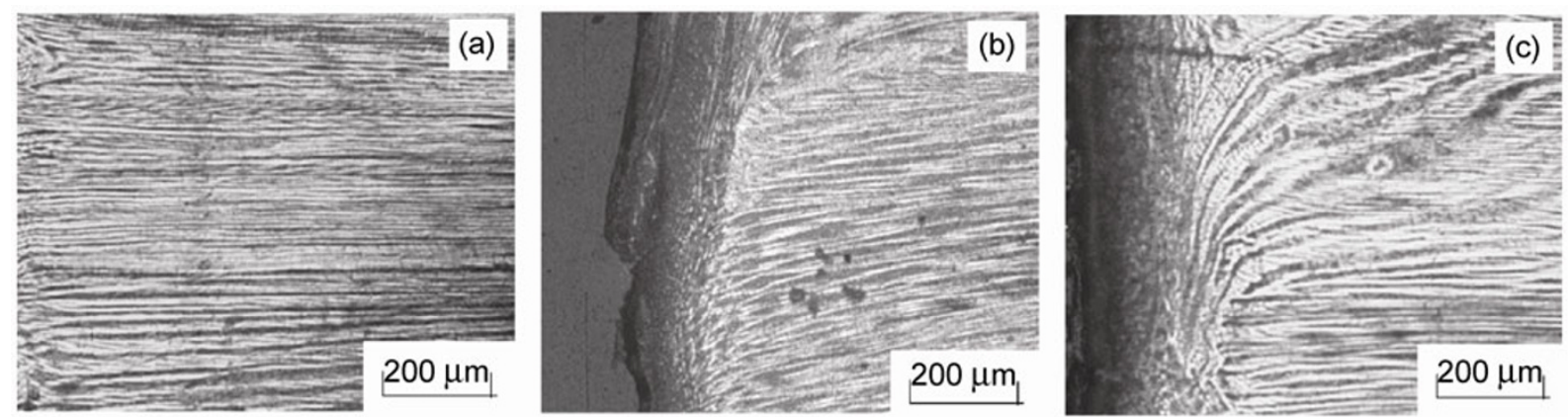

Fig. 13 Plastic deformation of copper: (a) original sample, (b) no current, (c) with current of $60 \mathrm{~A}$.

Table 2 Roughness of worn surfaces under different conditions.

\begin{tabular}{cccccc}
\hline No. & $\begin{array}{c}\text { Speed } \\
(\mathrm{m} / \mathrm{s})\end{array}$ & $\begin{array}{c}\text { Current } \\
(\mathrm{A})\end{array}$ & $\begin{array}{c}\text { Load } \\
(\mathrm{N})\end{array}$ & $\begin{array}{c}\text { Surface } \\
\text { roughness } \\
S_{\mathrm{a}}(\mu \mathrm{m})\end{array}$ & $\begin{array}{c}\text { Surface } \\
\text { roughness } \\
S_{\mathrm{q}}(\mu \mathrm{m})\end{array}$ \\
\hline 1 & 40 & 80 & 40 & 1.880 & 2.77 \\
2 & 40 & 80 & 80 & 3.220 & 5.64 \\
3 & 40 & 40 & 60 & 0.678 & 1.10 \\
4 & 40 & 60 & 60 & 1.710 & 2.59 \\
5 & 40 & 80 & 60 & 2.860 & 3.64 \\
6 & 10 & 80 & 60 & 0.778 & 1.07 \\
7 & 20 & 80 & 60 & 1.990 & 2.77 \\
8 & 40 & 80 & 60 & 21.700 & 28.6 \\
\hline
\end{tabular}

In particular, when the sliding speed and current are higher, the sliding surfaces become considerably rougher, which indicates the occurrence of severe wear and presence of poor electrical contacts; these result in poor triboelectric behavior.

Figure 14 shows the relationship between the surface quality and triboelectric behavior. It is revealed that both friction coefficient and current-carrying qualities worsen further when the sliding surface becomes rougher. Furthermore, it is noticed that the arc rate also tends to increase with an increase in the surface roughness, which suggests that a rougher surface promotes the formation of electric arcs.
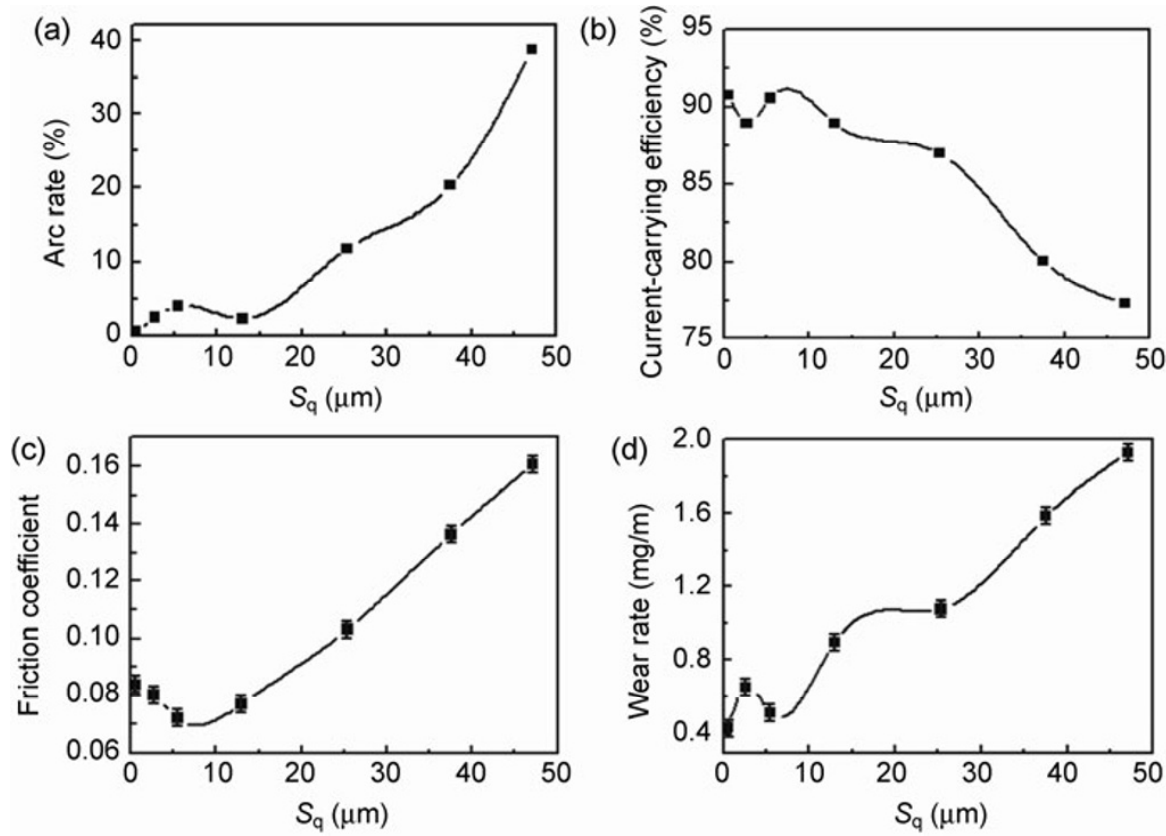

Fig. 14 Relationship between surface quality and triboelectric quality: (a) arc rate, (b) current-carrying efficiency, (c) friction coefficient, (d) wear rate. 
Summarily, the surface behavior of triboelectric pairs includes the following: oxidation, plastic deformation, melting, arc discharge, and so on. The existence of such multiple mechanisms complicates the analysis of surface contact behaviors. However, it can be concluded that all the factors that induce surface roughness worsen both tribological and electric conductivity behaviors, i.e., a rougher surface will result in poor triboelectric behavior.

It is well known that frictional and electrical contacts depend on the actual contact area or the actual contact ratio. With regard to determined deformation, a rougher surface implies lower actual contact ratio. From the viewpoint of contact points, a lower actual contact area leads to severe loading concentration, which includes thermal load, stress, and current density: A combination of these loading concentrations deteriorate both tribological and electric conductivity behaviors, thereby deteriorating the triboelectric behavior.

With regard to oxidation, significantly oxidized surface films increase the electric contact resistance, which not only decreases the electric conductivity but also increases the surface temperature due to high electric resistance, thereby worsening the tribological properties.

\subsection{Frictional arcs}

Figure 15 shows the surface morphologies eroded by (a) a single arc, (b) multiple arcs, and (c) no arc erosion. Material erosion induced by arcs includes melting, evaporation splash, gasification, and oxidation due to arc heat. Arc erosion is closely related to the arc intensity and duration [11]. The intensity and duration of the electric arc are directly determined by the energy input to the particular area. Further, the degree of arc erosion is also associated with the material properties (Figs. 10(d)-(h)). The local electric arc heat increases the surface temperature; furthermore, this local heat causes the material to liquefy or gasify: All these factors lead to material loss and destroy the contact integrity, i.e., worsen the electrical contact.

The arc-starting conditions are important in the study of triboelectric problems. From the experimental observations, it can be shown that arcs are produced under the following conditions: Speed is greater than $30 \mathrm{~m} / \mathrm{s}$, load is less than $150 \mathrm{~N}$, and current is greater than $20 \mathrm{~A}$. When observed during the experiments, the arcs appear visible to the naked eye.

The plots of the current signals and arc light intensity observed in triboelectric pairs are shown in Fig. 16. Partial enlargements of these plots are shown in Fig. 17.
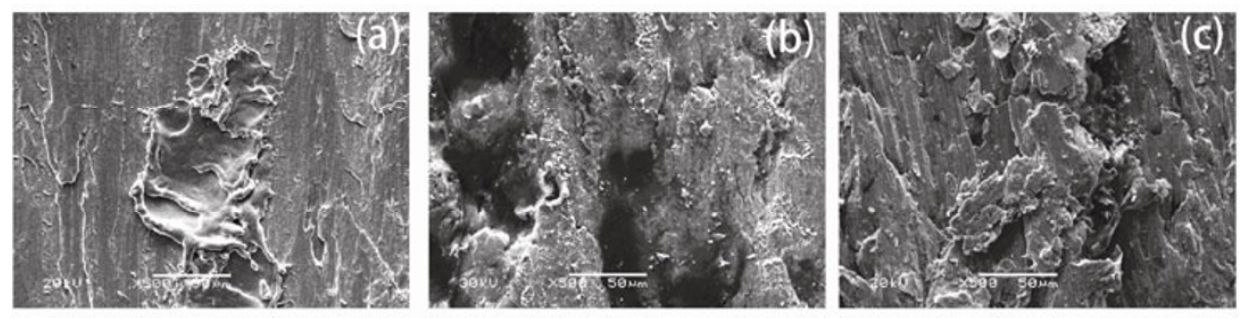

Fig. 15 Trace generated by different arcs: (a) large pit, (b) tiny trace, (c) no trace.

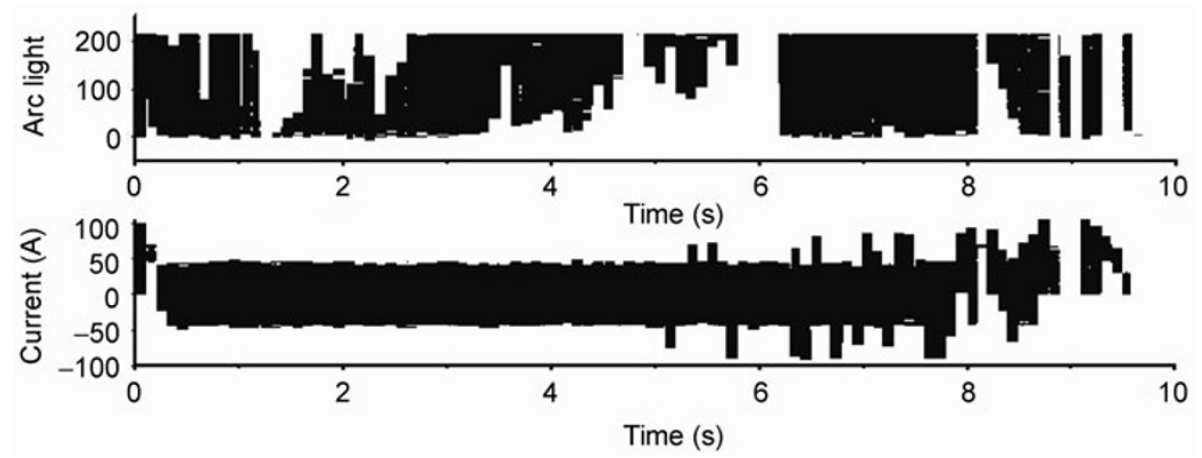

Fig. 16 Signals of current and arc light in triboelectric pairs. 

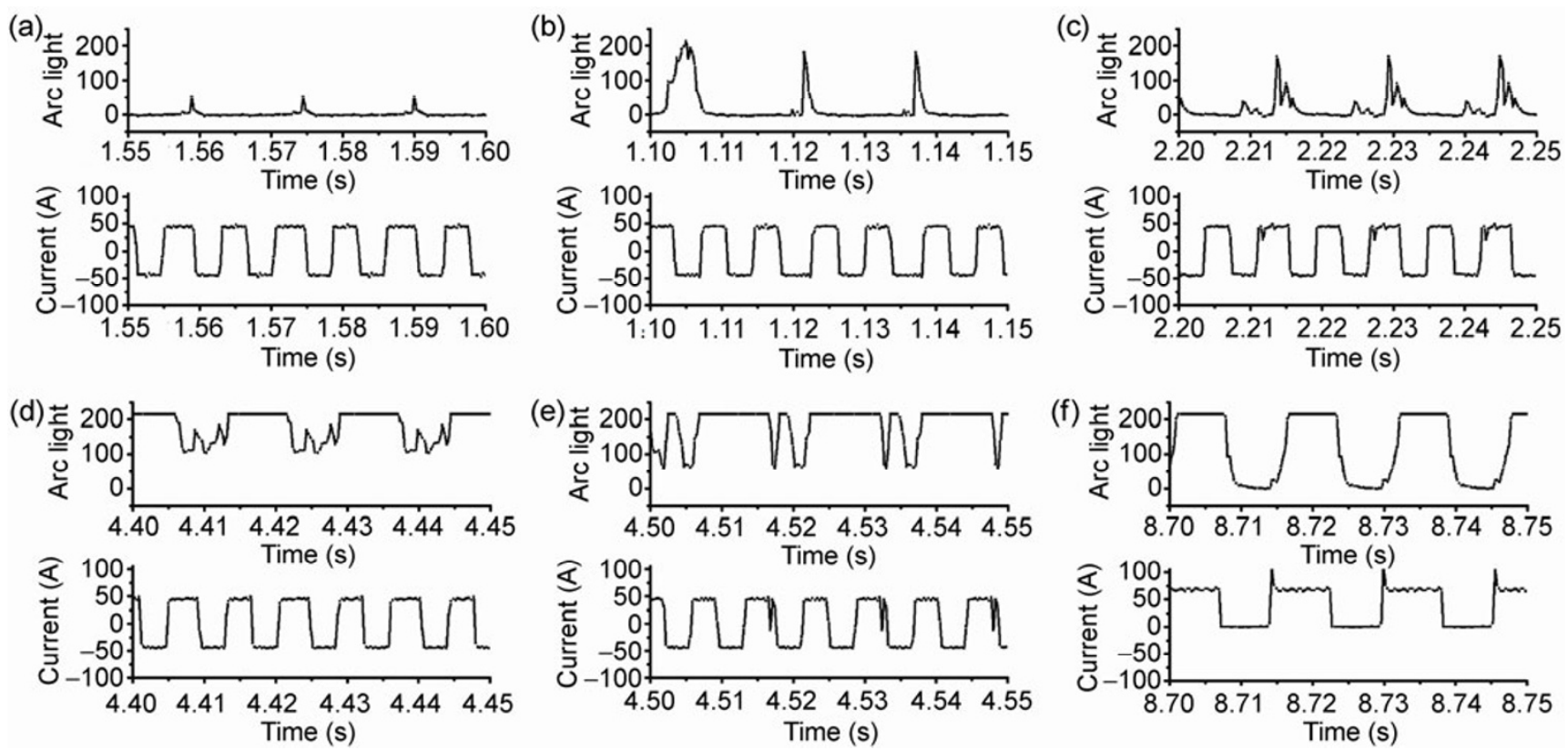

Fig. 17 Partial enlargement of signals of current and arc light: (a) no arc and normal current, (b) small arc and normal current, (c) small arc and abnormal current, (d) strong arc and normal current, (e) strong arc and abnormal current, (f) strong arc and no current.

Clearly, the duration and intensity of the arcs are small when a normal current is present (Fig. 17(a)), which indicates an optimal frictional contact and the type of electrical conductivity is contact conduction. Figs. 17(b) and 17(c) show short-duration high-intensity arcs: Evidently, the frictional contact is appropriate and the type of electrical conductivity is mainly contact conduction. Continuous arcs with strong intensities are shown in Figs. 17(d) and 17(e): In this case, the frictional contact is worse and the main type of electrical conductivity is arc conduction. A discontinuous arc with strong intensity is shown in Fig. 17(f): Here, the frictional contact is the worst and arc conduction controls the electrical conduction in the absence of the mean arc electric current. One more important phenomenon is that the occurrence of arcs induces electrical waveform distortion: Certain random waves are observed in the presence of arcs.

Figure 18 shows the relationship between the dynamic arc energy and friction coefficient of C/C material. The correlation coefficient of 0.6823 suggests that a proportional relationship exists between the

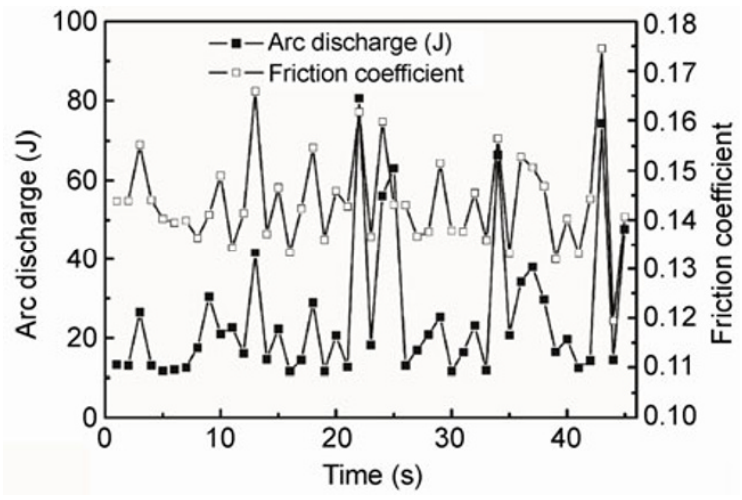

Fig. 18 Relationship between dynamic arc energy and friction coefficient.

dynamic arc energy and friction coefficient. This indicates that the arc energy can be used as an influencing parameter on tribological processes.

Figure 19 shows the relationship between the wear rate and arc energy. Clearly, the wear rate is proportional to the arc energy. The higher the arc energy, the severer the wear loss is. 
(a)

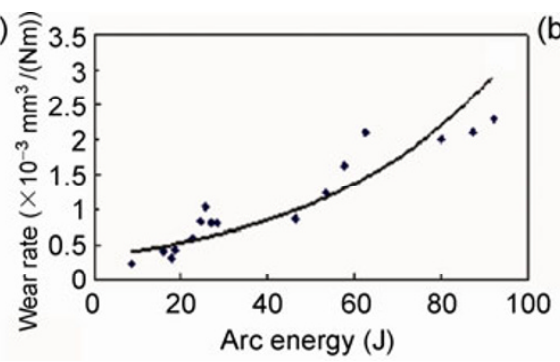

(b)

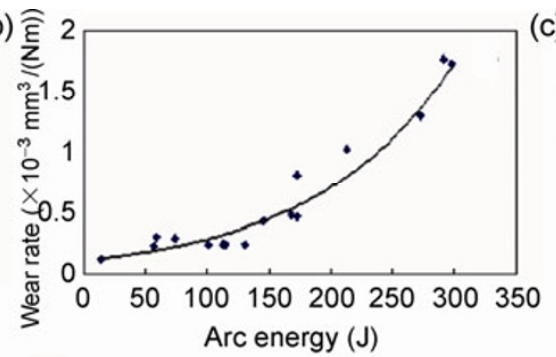

(c)

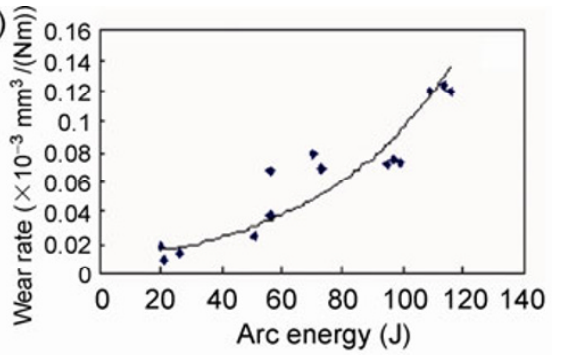

Fig. 19 Relationship between arc energy and wear rate: (a) PM material, (b) MC material, (c) C/C material.

\section{Conclusions}

(1) Tribological behaviors and electrical conduction behaviors exhibit complicated interrelationships: Deterioration in the servicing conditions (pressure, voltage, or current) has an obvious influence on the tribological and electrical behaviors. High sliding speeds and large electrical currents can worsen the tribological and electrical conductivity properties in triboelectric pairs.

(2) The triboelectric contact consists of frictional and conducting contacts, and the concentration of loads such as frictional heat, stress, and current density deteriorate both tribological and electrical contacts.

(3) Electric arcs play a very important role in influencing the triboelectric behaviors. High-intensity arcs can worsen the current-conducting quality and wear resistance. The influence of arcs on the triboelectric behavior is mainly due to the deterioration in the contact surface, which can occur due to oxidation and melting, finally resulting in rougher contact surfaces.

\section{Acknowledgements}

The authors gratefully acknowledge the National Natural Science Foundation of China (Nos. U1034002 and 50902133).

Open Access: This article is distributed under the terms of the Creative Commons Attribution License which permits any use, distribution, and reproduction in any medium, provided the original author(s) and source are credited.

\section{References}

[1] Song K X, Xing J D, Dong Q M, Liu P, Tian B H, Cao X J. Optimization of the processing parameters during internal oxidation of $\mathrm{Cu}-\mathrm{Al}$ alloy powders using an artificial neural network. Mater Des 26: 337-341 (2005)

[2] Hou Y P. The marketable situation and development of high voltage switchgear in China. Electrical Equipment 8(3): 101-103 (2007)

[3] Guo M H, Ding Y T. Research on the dry sliding friction and wear behaviour of copper alloy wire. Foundry Technology 29(4): 512-515 (2008)

[4] Shunichi K, Koji K. Effect of arc discharge on wear rate of $\mathrm{Cu}$-impregnated carbon strip in un-lubricated sliding against $\mathrm{Cu}$ trolley under electric current. Wear 216:172-178 (1998)

[5] Shangguan B. Study on damage mechanisms of the materials under coupling condition of current carrying and friction. PhD Thesis. Xi'an: Xi'an Jiaotong University, 2011.

[6] Azevedo C R F, Sinatora A. Failure analysis of a railway copper contact strip. Eng Fail Anal 11: 829-841 (2004)

[7] Jin X S, Guo J, Xiao X B, Wen Z F, Zhou Z R. Key scientific problems in the study on running safety of high speed trains. Engineering Mechanics 26 (Sup. II): 8-25 (2009)

[8] Fisher J, Gibson E D. Electrode erosion in high current. Wear 29: 48-52 (1927)

[9] Landly I T. Contact Wire wear on electric railroad. AIEE 10: 756-759 (1929)

[10] Kubo S, Kato K. Effect of arc discharge on the wear rate and wear mode transition of a copper-impregnated metallized carbon contact strip sliding against a copper disk. Tribol Int 32: 367-378 (1999)

[11] Kubo S, Kato K. Effect of arc discharge on wear rate of $\mathrm{Cu}$-impregnated carbon strip in unlubricated sliding against $\mathrm{Cu}$ trolley under electric current. Wear 216: 172-178 (1998) 
[12] Dong L, Chen G X, Zhu M H, Zhou Z R. Wear mechanism of aluminum-stainless steel composite conductor rail sliding against collector shoe with electric current. Wear 263: 598603 (2007)

[13] Yasar I, Canakci A, Arslan F. The effect of brush spring pressure on the wear behaviour of copper-graphite brushes with electrical current. Tribol Int 40: 1381-1386 (2007)

[14] Da H H, Rafael M. A novel electrical contact material with improved self-lubrication for railway current collectors. Wear 249: 626-636 (2001)

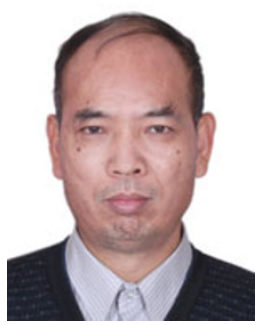

Yongzhen ZHANG. He is a professor of Henan University of Science and Technology, who received his
[15] Shangguan B, Zhang Y Z, Xing J D, Chen Y, Sun L M. Comparative study on wear behaviors of metal-impregnated carbon material and $\mathrm{C} / \mathrm{C}$ composite under electrical sliding. Tribol Trans 53(6):933-938 (2010)

[16] EN50367: Railway application-current collection systemstechnical criteria for the interaction between pantograph and overhead line.

PhD degrees in $\mathrm{Xi}^{\prime}$ an Jiaotong University in 2001. His current researches cover the dry sliding of material and antiwear materials. 